\title{
A educação ambiental e o desporto na natureza: Uma reflexão crítica sobre os novos paradigmas da educação ambiental e o potencial do desporto como metodologia de ensino
}

\author{
Paulo Filipe Rosa* \\ Luís Alberto Dias Carvalhinho**
}

\begin{abstract}
Resumo: A ideia de que a mera transmissão de conhecimentos e competências teóricas são suficientes para alcançar o comportamento pro-ambiental está actualmente refutada. Outros fatores como o ensino vivencial e experiencial são fundamentais para que se alcancem estes objectivos. Neste campo, o desporto na natureza poderá constituir uma das metodologias para o seu ensino. O presente artigo constitui uma aproximação teórica e crítica dos atuais paradigmas de ensino da educação ambiental e do potencial do desporto como metodologia de ensino. As conclusões revelam que os benefícios do desporto na natureza se cruzam com os objectivos da educação ambiental sobretudo numa fase de aquisição de consciência ambiental.
\end{abstract}

Palavras-chave: Natureza. Educação Ambiental. Esportes.

\section{INTRODUÇÃo}

Uma das questões fundamentais dos nossos dias é de que os problemas ambientais estão estruturalmente ancorados à sociedade e às nossas formas de vida (JENSEN; SCHNACK, 1997). Este fato tem levado a que cada vez mais se reflita no sentido de se encontrarem soluções em relação à maior complexidade destes assuntos, constituindo motivo de reflexão no debate acerca da educação ambiental a nível internacional (SANDELL; ÖÖHMAN,

\footnotetext{
Instituto Politécnico de Santarém. Escola Superior de Desporto de Rio Maior. Rio Maior, Portugal. E-mail: prosa@esdrm.ipsantarem.pt

"Instituto Politécnico de Santarém. Escola Superior de Desporto de Rio Maior. Rio Maior, Portugal. E-mail: Icarvalhinho@esdrm.ipsantarem.pt
} 
2010). Novos paradigmas educacionais têm emergido entre a comunidade científica, de onde resultam diferentes visões e novas problemáticas (LEE; WILLIAMS, 2001) que tendem cada vez mais para uma interação complementar entre o ensino teórico (transmissão direta de conhecimentos) e o cada vez mais aceite, ensino vivencial e experiencial como proposto por Lave e Wenger (1991) na exploração do conceito de "Situated Learning".

No outro lado do espetro, encontramos as práticas desportivas em contato com a natureza, a que neste texto denominamos de Desporto na Natureza, em clara expansão, em parte, derivado do aumento da investigação científica (MARINHO, 2008). Entre estudos associados à formação profissional dos técnicos (CARVALHINHO, 2006) à sua envolvência e estreita ligação com o setor comercial e com o turismo (BETRÁN; BETRÁN,1999; PRÖBSTL et al., 2010; COLE, 1996) até à sua gestão no meio natural (MANNING, 2007; HAIDER; PAYNE,2009) encontramos um conjunto de estudos de caráter interpretativo, que procuram cada vez mais refletir e conhecer os benefícios e as razões de aderência a este tipo de práticas assim como compreender de melhor forma as interações que ocorrem entre o Homem, enquanto praticante desportivo e a natureza (TAHARA; FILHO, 2009; BRASIL;CARVALHO,2009). Neste âmbito, verificamos uma série de trabalhos que procuram estabelecer uma relação entre a prática de desportos na natureza e a responsabilidade e consciência ambiental dos seus praticantes (LEE, 2011; FERREIRA, 1998; BRYMER; GRAY, 2010).

Neste contexto, Carvalhinho, Sequeira, Serôdio-Fernandes e Rodrigues (2010) são da opinião de que a prática desportiva em contato com a natureza valoriza um conjunto de sensações como o prazer, a satisfação, o bem-estar e a saúde, refletindo assim, uma necessidade de compensação de um sistema de vida mais sedentário e centrado na vida urbana.

Tahara e Filho (2009), ao citar Schwartz (2002) e no mesmo sentido que os autores citados anteriormente, enfatiza a necessidade 
dos indivíduos na procura de atividades de lazer, que pelas suas características (e.g. liberdade, prazer, lucidade) tem uma intervenção direta na qualidade de vida.

Consideramos que existe assim um valor intrínseco associado à vida ao ar livre, que não pode ser encontrado junto da sociedade urbanizada e industrial e que reflete a forma como os indivíduos entendem e percecionam o próprio espaço natural. Neste campo, Sandell e Öhman (2010) referem que esta nova relação entre o Homem e a natureza não se resume a meros fatos, sendo que nela existe um conteúdo moral, estético e emocional. Jensen e Schnack (1997) assumem que este mesmo valor intrínseco conduz para o respeito, à humildade e ao próprio pensamento, ações que na nossa opinião fazem falta nas sociedades atuais.

É com base na possível sinergia entre o desporto na natureza e os novos paradigmas de ensino da educação ambiental, que se desenvolve este ensaio. Partindo de uma revisão de literatura de âmbito multidisciplinar (e.g. áreas da educação ambiental, desporto, pedagogia, gestão de espaços naturais e turismo de natureza) estabelecemos como objetivos, i) a compreensão do binómio natureza-desporto e os seus benefícios, ii) a compreensão do conceito de educação ambiental e os novos paradigmas de ensino e aquisição dos comportamentos pro-ambientais, e iii) os meios pelos quais a prática desportiva pode ser parte integrante do processo de educação ambiental.

\section{Compreender o binómIO NATUREZA-DESPORTO COMO FONTES DE BENEFÍCIOS PARA O HOMEM}

Do ponto de vista antropocêntrico ou materialista, o mundo natural é visto como "outro" pela humanidade, onde a natureza existe apenas para benefício humano (MATHEWS, 2006). Rodrigues e Junior (2009) comentam esta visão, e fazendo referência à crise ambiental contemporânea defendem que "[...] é em grande parte, resultante de uma relação desintegrada entre a sociedade e o meio ambiente, sustentada por uma compreensão do mundo que aponta 
para uma "lógica de dominação" do ser humano sobre a natureza" (GUIMARÃES, 2004 apud RODRIGUES; JUNIOR, 2009, p.988). Este fato, na opinião dos mesmos autores, é culpa da cultura industrial capitalista moderna, fortemente ligada a uma ideologia individualista e que construiu uma representação mecânica do ser humano, diminuindo a sua capacidade de se relacionar com o outro (social) e com o mundo (ambiental) visão esta também partilhada por Marinho (2008).

Neste ensaio partimos de uma visão diferenciada da natureza, partilhando da posição de Brymer e Gray (2010). Os autores desenvolveram nos seus trabalhos, uma abordagem aos desportos extremos e à sua relação com a natureza, defendendo uma diferente perspetiva a que, citando Oelschlaeger (1992), a determinam como "perspetiva ecocêntrica" que se opõe claramente ao antropocentrismo. Esta reconhece que a natureza tem um conjunto de valores intrínsecos e que não existe única e exclusivamente como recurso para a humanidade, onde as montanhas, os rios e as ondas têm um valor inerente, onde a humanidade é parte desta natureza (OELSCHLAEGER, 1992 apud BRYMER; GRAY, 2010). Brymer e Gray (2010), ao realizar entrevistas junto de participantes em desportos extremos, reconheceram que estes entendem os recursos naturais como algo com personalidade própria como demonstra a citação original de um dos entrevistados: "The place is still powerful, it has energy and it's giving back to you" (BRYMER;GRAY, 2010, p.369). A adoção desta forma de pensar é também espelhada, por exemplo, ao nível da gestão de espaços naturais para a prática desportiva. Segundo Kyle et al. (2004), ao longo da última década, sobretudo na realidade americana, vários autores tem denotado um significante interesse sobre este novo paradigma social que conduz para a filosofia inerente à gestão dos recursos naturais. Este coloca grande ênfase na compreensão dos significados subjetivos, emocionais e simbólicos associados aos espaços naturais e aquilo que leva as pessoas a esses mesmos espaços, originando assim um conjunto de informação mais completa e extremamente útil para a gestão 
O contato com a natureza vista desta forma leva à reflexão do homem acerca de si próprio e dos problemas do quotidiano e da sociedade em geral (SANDELL; ÖHMAN, 2010), levando os diferentes participantes a interagir (interação social) num contexto mais livre de preconceitos (JENSEN; SCHNACK, 1997).

Encontramos assim, um conjunto de benefícios associados à reflexão, ao bem-estar, à introspeção e à socialização.

No domínio das práticas físicas e desportivas, consideramos pertinente desenvolver um pouco sobre o interessante conceito apresentado por Rodrigues e Junior (2009), de "Ecomotricidade". Segundo estes, podemos entender a ecomotricidade como as práticas corporais desenvolvidas com intencionalidade, relacionadas com processos educativos de reconhecimento das relações Homem natureza e que primam pela sinergia entre educação ambiental, motricidade humana e pedagogia dialógica.

Ao explorar o conceito, encontramos uma valorização da prática corporal na natureza como compreensão do próprio corpo e como caminho para uma relação Homem-natureza mais respeitosa. Pensar a ecomotrocidade como a motricidade humana em relação à natureza significa o reconhecimento e a incorporação dos problemas ambientais, o que significa que o indivíduo não só compreenda quais são os problemas ambientais contemporâneos mas que os reconheça como seus problemas (RODRIGUES; JUNIOR, 2009), implicando ainda, uma compreensão por parte do indivíduo, que o movimento e o corpo humano são partes integrantes do próprio ambiente, porque o Homem também o é.

Já a saúde é valorizada neste contexto por Rodrigues e Darido (2006) , defendendo que esta deve envolver a complexidade das relações entre o indivíduo e o meio ambiente. Esta valorização é também partilhada por Sandell \& Öhman (2010), que de uma forma não focada especificamente no desporto, defendem que a vida em contato com a natureza tem um conjunto de benefícios para a saúde humana, física e mental. Num mesmo sentido, Rodrigues e Darido (2006) apontam que o desporto de aventura, sobretudo aquele 
realizado junto à natureza, representa mais uma possibilidade de aproximação entre esta e o indivíduo, devido à interação com os elementos naturais e as suas variações promovendo assim o respeito pelo meio.

Assim, facilmente identificamos que as práticas de desporto na natureza apresentam um conjunto de características que facilmente se cruzam com os benefícios que advém do já referido contato com a natureza.

\section{A NATUREZA COMO PALCO DA UMA PRÁTICA DESPORTIVA EMERGENTE}

Soares e Paixão (2010) com base na perspetiva de Elias e Dunning (1990), defendem que as atividades de aventura na natureza ganham cada vez mais adeptos, devido ao facto de serem imprevisíveis e excitantes e estarem abertas a qualquer pessoa seja qual for a idade ou sexo (ELIAS; DUNNING, 1990 apud SOARES; PAIXÃO, 2010).

O crescimento na procura dos desportos na natureza, quer num âmbito puramente recreativo quer turístico é sinal da valorização dos benefícios referidos. Há cerca de 15 anos atrás, nos Estados Unidos da América, um estudo de Cole (1996) acerca das tendências nas práticas de recreação e de lazer, reconheceu o aumento da procura de espaços protegidos para atividades como o acampamento, caminhada, a escalada ou o Mountain Bike. Contrastando com a realidade europeia, resultados mais recentes de Probstl et al. (2010), identificam o crescimento de novos setores do turismo de natureza, fortemente associados aos desportos na natureza. A mesma posição é defendida por Marinho (2008) que, com base em pesquisa realizada pelo Ministério do Meio Ambiente Brasileiro, refere o crescimento expressivo da visitação em áreas naturais no Brasil e no mundo e que os desportos de aventura na natureza enquadram-se entre os segmentos mais promissores do mercado de turismo, com um crescimento mundial estimado entre $10 \%$ e $30 \%$ ao ano. 
Pode-se assim considerar, que o turismo e a recreação baseados na fruição da natureza são uma indústria crescente e global, particularmente dependente dos atributos (características físicas do território) que o meio natural tem para oferecer (EAGLES,2002; ROSA;ALMEIDA et al.,2011).

No entanto e paradoxalmente, a principal ameaça à integridade ecológica é o uso humano (DEARDEN;ROLLINS,2009). É neste sentido, que a consciência e a responsabilidade ambiental se demonstram essenciais.

Existem nas posições dos diversos autores agora citados, uma clara tendência para a valorização das atividades desportivas em contato com a natureza, como fonte potencial de bem-estar, divertimento, liberdade e imprevisibilidade, características que se afastam ligeiramente daquilo que é o desporto competitivo. Mais importante do que isso e indo ao encontro dos objetivos da presente reflexão, está o contato direto com a natureza, como forma de "aproximação", sobretudo interior, entre o Homem e a natureza e no sentido da interação. Não discordando da posição de Rodrigues e Darido (2006), podemos para já, no nosso entender, olhar a prática desportiva na natureza, como uma fonte de "aproximação" e de "interação" do binómio Homem-Natureza não podendo assumir que a prática por si só leva ao "respeito" pelo meio natural. Parece-nos que a possibilidade de se poderem desenvolver atividades desportivas em contato com a natureza é um fator basal para que outros benefícios que advém desta situação possam ser potenciados através deste tipo de práticas.

O crescimento na procura destas atividades justifica por si só a necessidade de investimento científico e profissional a vários níveis, incluindo logicamente, aquele que se revela um fator de base para que estas atividades possam existir: a natureza e a educação daqueles que com ela interagem. No presente momento não nos é possível aferir acerca da eficácia e efetividade da prática desportiva na educação ambiental. No entanto, as diferentes leituras encaminhamnos para essa possibilidade. 


\section{As PRÁTICAS DESPORTIVAS E A TRANSMISSÃO DE UMA CONSCIÊNCIA| CONHECIMENTO AMBIENTAL}

Segundo Kollmuss e Agyeman (2002), inúmeros modelos teóricos tentaram explicar a lacuna existente entre a consciência/ conhecimento ambiental e a adoção de comportamentos proambientais ou ambientalmente responsáveis, e que, apesar das várias centenas de estudos desenvolvidos, ainda não existe uma explicação definitiva do processo. Não é objetivo desta pesquisa discorrer acerca dos diferentes modelos de comportamento pro-ambiental, no entanto consideramos fundamental refutar a ideia inerente aos primeiros modelos, que defendiam uma relação linear e consequente entre "Conhecimento ambiental - Atitude ambiental - Comportamento próambiental", que, segundo os mesmos autores, provaram rapidamente estar errados e que outros fatores (e.g. fatores internos inerentes à personalidade do individuo ou fatores externos inerentes a fatores económicos, políticos e sociais) eram necessários para compreender a aquisição destes comportamentos.

Por outro lado, quer na perspetiva de Kollmuss e Agyeman (2002), quer na opinião de Ferreira (1998), a consciência ambiental é antes de mais o ponto de partida para a educação ambiental. É neste prisma que abordamos alguns estudos associados a diferentes práticas desportivas na natureza e cujos resultados apontam para a aquisição de uma relação harmoniosa com a natureza e alguns indicadores de consciência ecológica.

Brasil e Carvalho (2009), com o intuito de analisar as interações entre a natureza e grupos de surfistas, reconheceram que as suas práticas remetem para a busca pelo sentido da vida na emoção e aventura para além dos valores e princípios determinados pela ciência e pelo mercado. Neste sentido, o surfista está mobilizado, presente e envolvido com a experiência, exercendo no mar, a imaginação, a criação e o encontro consigo e com a natureza. Stewart e Craig (2000) observaram que as pessoas que estão expostas 
frequentemente ao contato com o meio natural são mais propícias às atitudes conservacionistas e comportamentos pro-ambientais do que aqueles que passam mais tempo em ambientes construídos. Também Lee (2011), num estudo sobre práticas recreativas de turistas numa área natural, verificou que o envolvimento nestas atividades afetava direta e significativamente o compromisso conservacionista e ao mesmo tempo os comportamentos pro-ambientais.

Por seu turno, Ferreira (1998) verificou que a caminhada é uma prática ideal para a educação ambiental, se a intenção passar por introduzir as pessoas no meio natural e nos seus problemas. Defende também que a educação é um fator essencial para contribuir para um aumento do conhecimento ambiental, mas que, no entanto, a aquisição de conhecimentos através da experiência e envolvimento nas atividades é essencial. Brymer e Gray (2010) ao concluírem que a prática de desportos extremos, num grupo de veteranos, era o contexto adequado para apreciarem a conexão entre a humanidade e o mundo natural, verificaram também que os participantes mantêm esta postura não só no momento da prática mas transferem-na para os acontecimentos do dia-a-dia da vida moderna. Light (2006), partindo do já referido conceito de "Situated Learning" verificou que a frequência e vivência num clube de surf australiano por jovens adolescentes, eram essenciais para a formação da sua identidade a vários níveis. Tahara e Filho (2009), noutra pesquisa acerca dos benefícios da prática de atividades físicas na natureza, reconheceram que $16 \%$ dos respondentes consideraram que o respeito pelo próximo e pelo meio natural se tinham tornado mais incidentes na sua vida após iniciarem estas práticas.

Neste âmbito, podemos reconhecer a aparente eficácia do contato com a natureza através das práticas desportivas, na aquisição de uma maior consciência ambiental. É fácil reconhecer também, que para uma aquisição efetiva desta consciência, é necessário o contato continuado com este tipo de práticas, não se limitando apenas à aquisição de competências teóricas e de forma pontual. 


\section{A eduCAÇão amBiental E PERSPETIVAS PEDAGÓGICAS}

Segundo Rodrigues e Darido (2006), os primeiros movimentos a considerar a contribuição do processo educativo relacionado com a questão ambiental, ocorreram em meados da década de 60, sendo que as referências básicas para a estruturação da educação ambiental como uma área do conhecimento aplicado encontram-se nos documentos produzidos pela UNESCO, especialmente na Carta de Belgrado, de 1976, e no documento produzido por Tbilisi, em 1983 e 1985. Em termos europeus, o exemplo dos países escandinavos é incomparável, podendo tomar como exemplo a Suécia, onde a democratização das organizações de outdoor e de outras responsáveis por este tipo de atividades se iniciou por volta dos anos 30, com o objetivo de sensibilizar o público para este tipo de práticas ambientais. Mais tarde, nos finais dos anos 60 e após a $2^{\text {a }}$ grande guerra, o interesse dos governos no planeamento e controlo das atividades de outdoor tornou-se mais evidente, sendo que em meados da década de 80, uma componente educacional começou a ser estabelecida em cerca de 90 escolas primárias e secundárias em toda a Suécia (SANDELL; ÖHMAN, 2010).

No contexto educacional escolar, a educação ambiental temse tornado cada vez mais importante, surgindo diferentes paradigmas educacionais (LEE; WILLIAMS, 2001), e algumas propostas pedagógicas (RODRIGUES; DARIDO, 2006) com especial ligação à vertente da educação física escolar.

Apesar das preocupações e aparente desenvolvimento, o conceito de educação ambiental ainda apresenta diversas definições, sobretudo porque as posições ou as metodologias que se consideram efetivas neste âmbito são diversas e tem sido alvo de constantes mudanças, resultantes da cada vez maior investigação na área (JENSEN; SCHNACK, 1997). Rodrigues e Darido (2006) defendem a educação ambiental como uma necessidade de abordar os aspetos relacionados ao meio biofísico do Homem e as complexas relações que estabelecem, bem como as suas formas de interação com o ambiente a várias dimensões: politica, social e cultural. Como 
objetivos, são definidos, entre outros, a aquisição de conhecimentos, atitudes e valores sociais que levem à participação ativa na melhoria do meio ambiente (RODRIGUES; DARIDO, 2006). Lucas (1980/ 81 apud LEE; WILLIAMS, 2001) refere a diferença entre "educação sobre o ambiente", que consiste na aquisição de competências para essa mesma compreensão, e "educação no ambiente" que implica o contato direto e a vivência de situações reais.

No que concerne à evolução da educação ambiental, enquanto conteúdo de ensino formal, não formal ou informal, as leituras de Sandell e Öhman (2010), Jensen e Schnack (1997) e Rodrigues e Junior (2009), levaram-nos a identificar duas fases distintas.

Rodrigues e Junior (2009), tecem fortes críticas a uma primeira fase mais conservacionista, onde a sociedade é considerada apenas como "a soma dos seus indivíduos", onde a natureza é vista como algo intocável transcendente ao ser humano, quando no fundo, e na perspetiva destes autores, o ser humano faz parte dessa mesma natureza e deve ser visto como tal.

Esta fase carateriza-se sobretudo pela transmissão de valores, alteração de comportamentos e pela sensibilização, principalmente das crianças e jovens (SANDELL; ÖHMAN, 2009; JENSEN; SCHNACK, 1997; RODRIGUES; JUNIOR, 2009).

Jensen e Schnack (1997) defendem que a dimensão quantitativa da educação ambiental (e.g. redução do consumo de água e energia, a reciclagem, a racionalização dos transportes, entre outros) é importante, mas que isoladamente, se torna parca em termos de aprendizagem efetiva. Revelam também que se têm canalizado os esforços da educação para o aumento da ansiedade e preocupação nas crianças relativamente aos aspetos ambientais. No entanto, alguns estudos nórdicos têm demonstrado que esta não é a visão mais adequada, ficando a faltar uma componente de "ação", essa, que se pretende consciente e competente. Em correspondência com os autores anteriores, estão as alterações efetuadas nos diferentes modelos de comportamentos pro-ambientais adotados ao longo do 
tempo, como demonstrado por Kollmuss e Agyeman (2002) e as diferentes possibilidades curriculares apresentadas no trabalho de Lee e Williams (2001).

Referências semelhantes também foram encontradas no trabalho de Rodrigues e Darido (2006), referindo com assertividade que "seria ridículo acreditar que o simples contato com a natureza fosse condição suficiente para considerar o indivíduo como defensor do meio ambiente". Na leitura dos seus trabalhos, existe correspondência num aspeto que caracteriza fortemente as suas opiniões face às práticas mais conservacionistas da educação ambiental. Não desvalorizando a importância da alteração de comportamentos e atitudes (que frequentemente são observados quer nas escolas quer em campanhas de foro ambiental) é muito importante que a educação das crianças e jovens para a sustentabilidade seja muito mais do que isso. É essencial, que novas perspetivas pedagógicas consigam colmatar esta falha, numa doutrina que ainda hoje é fortemente aplicada em muitos países do mundo.

É neste momento que fazemos a transição para uma posição mais moderna e que, mediante as nossas leituras, ainda se encontra numa fase de evolução.

Nesta visão, a educação ambiental é mais do que simples alterações de comportamento e aprendizagem académica. Neste caso, defende-se a existência de uma componente qualitativa associada à reflexão, identificação de problemas e sua resolução. Os autores Jensen e Schnack (1997) desenvolveram um extenso trabalho de revisão, onde o objetivo principal foi refletir sobre novas práticas pedagógicas na educação ambiental, dando ênfase ao conceito de Action Competence como a base de um correto desenvolvimento destas, o que por nós, poderia ser traduzido como "Ação consciente e competente". Estes autores defendem que a educação ambiental deverá ser vista numa dimensão também qualitativa que deve levar os alunos a encontrar alternativas, formas de resolução e formas de participação, ou seja, considerar todo o processo como forma de compreensão e aprendizagem. Fazendo uma breve aproximação daquilo que são as competências sociais, 
defende que os jovens devem ser cidadãos ativos e conscientes, não só dos problemas, das atitudes corretas, mas na forma como determinados problemas podem ser resolvidos, dando ênfase a valores como o sentido prático e a proatividade. Poderíamos criar uma analogia entre a posição do autor e a realidade organizacional da certificação ambiental, cuja base de aplicação se baseia na conhecida metodologia PDCA (Plan, Do, Check and Act) (INSTITUTO..., 2005).

É neste contexto, que os autores Jensen e Schnack (1997) diferenciam o conceito de "Ação" da "Atividade". Ao observarmos o quadro 1, encontramos 2 dimensões: i) Dimensão horizontal (critérios 1 e 2) que diz respeito ao limite entre o comportamento e a ação, e a questão de saber se os próprios alunos decidem "fazer algo"; ii) Dimensão vertical (critérios 3 e 4), que se concentra sobre se o que "é feito" é dirigido a uma solução do problema real ou não. Logicamente, perante aquilo que tem sido discutido, a "ação competente" só existe quando o indivíduo (referindo-se ao estudante) é envolvido na decisão de determinada ação de foro ambientalista (Critério 2) e que essa ação tem de ter um efeito real sobre o problema (Critério 4). Quando isto não sucede, ou quando o individuo é levado a desenvolver determinado assunto por motivos, por exemplo, puramente académicos, então estamos perante, não uma ação consciente, mas sim uma atividade.

Quadro 1. Critérios (1,2,3 e 4) para a ocorrência da "Ação".

$$
\begin{gathered}
\text { Estudantes obrigados a fazer } \\
\text { algo (1) }
\end{gathered}
$$

Atividade apenas como um
contraponto ao ensino
académico (3)
Atividade destinada a
resolver um problema (4)

\begin{tabular}{|c|c|}
\hline ATIVIDADE & ATIVIDADE \\
\hline ATIVIDADE & AÇÃO \\
\hline
\end{tabular}

Fonte: Adaptado de Jensen e Schnack (1997) 
Também Rodrigues e Junior (2009) apresentam uma posição semelhante, direcionando-a para uma componente mais interativa entre as atividades desportivas e a natureza. Aparentemente tendem para uma visão mais "radical" da aprendizagem, onde o contato direto com a natureza, incluindo aquilo que tem de bom e de mau e que por vezes causa sofrimento (e.g. frio extremo, chuva, o desconforto) são formas de levar o individuo a respeitar de forma mais profunda o meio natural, contribuindo para a sua educação. Esta visão enquadra-se numa nova forma de conceber a educação ambiental associada a novas abordagens pedagógicas a que os mesmos autores citando Cascino (2000) determinam como "Pós-moderna". Esta abordagem, constitui-se como um "momento da educação que privilegia uma compreensão dos ambientes de maneira não excludente, não maniqueísta. Ou seja, que privilegia as relações democráticas que respeitam o indivíduo e o grupo...permitindo que novas necessidades coexistam no respeito e na harmonia, no conflito e na incorporação das divergências, no constante encontro/ desencontro promovido pelo diálogo" (CASCINO, 2000 apud RODRIGUES;JUNIOR,2009,p.990)

Para finalizar, devemos fazer referência ao trabalho de Sandell e Öhman (2010). Estes autores desenvolveram um projeto com o objetivo de contribuir para o conhecimento científico acerca das diferentes práticas de educação outdoor e educação ambiental decorrentes na Suécia e de uma forma mais geral nos restantes países escandinavos.

Uma análise prévia levou à seleção de três práticas para estudos futuros cuja análise individual constituiu a parte principal do estudo. Das três destacamos duas, diretamente associadas à prática desportiva e que retratam duas perspetivas que se enquadram na posição pós-moderna da educação ambiental: 1) Atividades Outdoor (incluindo desportivas) que potenciem o desenvolvimento das crianças: Este caso consistiu na observação de alunos de escolas suecas em atividades diversas ao ar livre e sujeitos a diferentes condições meteorológicas, entre elas o ski (sob temperaturas de cerca de $-20^{\circ} \mathrm{C}$ ). Em todas as atividades e dado o papel relevante e contínuo 
que a educação ambiental teve na vida destas crianças, observaram que não existiam quaisquer problemas na realização das tarefas e que os professores raramente tinham de intervir para explicar "como fazer". Aparentemente, este histórico associado ao contato com a vida ao ar livre levou a um conjunto de hábitos que se demonstram permanentes, potenciado o sentido prático dos indivíduos. Numa outra perspetiva, 2) Educação ambiental associada ao movimento radical outdoor $^{1}$ : Este caso vai ao encontro da perspetiva de Rodrigues e Junior (2009), na defesa de um lado mais extremo das atividades desportivas, sendo centrado sobretudo em adultos e caracterizado por experiências muito marcantes e de forte contato com a natureza (que importem risco, sensações fortes e aventura). $\mathrm{O}$ caso de estudo centrou-se em quatro estudantes do género feminino, de uma escola escandinava e no âmbito de um curso, que foram acompanhadas numa jornada de quatro dias, a pé e em autonomia, num ambiente invernal e com o mínimo material possível (ausência de tenda, fogão ou vestuário especifico), sendo que o material que levavam foi construído pelos mesmos com materiais ecológicos. Nos resultados, percebeu-se que o contato mais extremo e pessoal com a natureza pode providenciar oportunidades para uma reflexão crítica acerca da vida quotidiana e dos problemas da sociedade, neste caso específico, acerca dos consumos e hábitos da vida quotidiana.

Tendo em conta as diferentes perspetivas daquilo que deve ser a educação ambiental, torna-se importante do nosso ponto de vista, a conjugação e um investimento científico e experimental em ambas as visões, sobretudo na pós-moderna. Desta forma, poderão desenvolver-se metodologias eficazes que por sua vez originem atividades e conteúdos de aprendizagem efetiva na educação ambiental. A conjugação da presente discussão com as referências anteriores focadas na prática desportiva e nos benefícios do contato com a natureza, permite-nos traçar um caminho objetivo entre a educação ambiental e o desporto.

${ }^{1}$ Caracterizada pela visão norueguesa da "Ecologia profunda"

Movimento, Porto Alegre, v. 18, n. 03, p. 259-280, jul/set de 2012. 
Neste sentido, arriscamo-nos a fazê-lo, visto que: i) A prática desportiva na natureza poderá potenciar alguns benefícios como a reflexão, a preservação, o contacto direto, a aventura, o risco (mais ou menos extremo), o culto do corpo e do movimento, ou seja, a vivência continua com a natureza quer em momentos prazerosos quer de conflito. Estes são valores inerentes à posição pós-moderna da educação ambiental; ii) Por outro lado, dado o fato de as atividades desportivas na natureza serem potenciais causadoras de alterações (físicas e paisagísticas) no meio ambiente (LEUNG; MARION, 2000), revela-se fundamental que no planeamento destas atividades se inclua uma dimensão ambiental. O trabalho prévio de reconhecimento dos potenciais impactos e estratégias para a sua mitigação e posteriormente a sua aplicação no terreno são fatores que vão ao encontro da importância do "processo" já referido na visão pósmoderna da educação ambiental; iii) $\mathrm{O}$ variado leque de atividades e de contextos físicos, meteorológicos e até sociais que caraterizam os desportos na natureza, abrem a possibilidade de, inerente a esta diversidade, se incluir também a educação ambiental de uma forma muito rica e diversa.

\section{Considerações finals}

O desporto, a natureza e a educação ambiental, revelam-se assuntos complexos, distintos, mas com uma ligação aparente.

Acreditamos que o desporto na natureza poderá potencializar a educação ambiental, servindo como uma das várias (ou muitas) metodologias que poderão ser utilizadas para este fim. Para isso, é importante que se compreendam, antes de mais, os novos desafios da educação ambiental e os fundamentos pelo qual se regem os novos paradigmas de ensino neste setor educacional. A crença de que o conhecimento e as competências ambientais transmitidas de forma direta (caso do ensino tradicional) são suficientes para a obtenção de uma consciência ambiental e consequentemente a adoção de comportamentos pro-ambientais está parcialmente refutada. Aparentemente, uma aproximação Homem-Natureza, 
baseada na conjugação dos princípios de "Ação consciente e competente" (Action Competence) e de "Ensino vivencial" (Situated Learning) revelam-se como uma das principais e mais efetivas abordagens para as quais o desporto na natureza poderá contribuir significativamente. Somente após esta consciencialização podemos considerar a inclusão do desporto como ferramenta de educação para o ambiente, para a sustentabilidade e para a cidadania. Os contextos de aplicação apresentam-se variados, desde a escola, às atividades desenvolvidas nos âmbitos empresariais (turismo) ou associativos.

Kollmuss e Agyeman (2002), na tentativa de analisar os diversos modelos teóricos que explicam o comportamento pro-ambiental, constituíram uma proposta teórica que inclui muitos dos fatores considerados em modelos anteriores. Neste caso, identificam um conjunto de barreiras ao comportamento pró-ambiental que advém de factores internos e externos, nomeadamente: i) falta de consciência ambiental; ii) falta de possibilidades (entenda-se como oportunidades/vivências) internas e externas; iii) falta de feedback acerca dos comportamentos ambientais; e, com mais importância, iv) a existência de antigos padrões comportamentais. Mediante as leituras realizadas, parece-nos que o desporto na natureza poderá contribuir para a minimização destes fatores inibidores. Ao nível escolar, poderá contribuir para o aumento de oportunidades externas através de ações de foro ambiental e da própria transmissão de conhecimentos, partindo por exemplo, da inclusão dos desportos na natureza nas aulas de educação física ou da identificação e resolução consciente e responsável de problemas ambientais inerentes ao ambiente escolar. Ao nível associativo, poderá aproximar os jovens e as crianças dos clubes desportivos e de aventura, e desenvolver ações que permitam aos jovens conhecer e viver a natureza, contrariando desde estas idades, o efeito dos "antigos padrões comportamentais". Ao nível empresarial e sobretudo em termos turísticos, poderá aproveitar as novas tendências de mercado e promover serviços que permitam aos turistas um contato direto e consciente com a natureza. Não menos importante, a sensibilização 
e formação complementar dos responsáveis das diferentes organizações pode revelar-se algo pertinente para que estas ações possam efetivamente ter lugar.

O trabalho aqui apresentado pretendeu expor a problemática da educação ambiental atual e a sua possível relação com o desporto na natureza.

É importante referir, que não se tentou aferir a relação efetiva da prática desportiva na natureza como forma de educação para o ambiente ou no ambiente. Procurou-se sim, lançar uma perspetiva teórica deixando em aberto alguns temas que poderão e deverão, em nosso entender, ser objeto de estudo. Utilizamos o termo "deverão" porque aparentemente a pesquisa efetuada neste âmbito é ainda escassa, mesmo em termos internacionais, existindo assim poucos casos práticos e de investigações associados ao trabalho de terreno, assim como propostas metodológicas de atuação.

Neste sentido consideramos relevante que novos trabalhos sejam realizados neste campo de investigação, a saber: i) Um conhecimento dos novos paradigmas de investigação em educação ambiental; assim como, ii) a compreensão desta corrente educativa no caso nacional (caso português) demonstra-se ser relevante, para posteriormente compreender o desporto na natureza e o seu potencial contributo. Numa fase seguinte, parece-nos que o caminho a seguir, poderá passar por, iii) desenvolver e apresentar uma proposta teórica de metodologias e consequentes validações com aplicações práticas no terreno. 
Environmental education and nature-based sport: A critical reflection on the new paradigms of environmental education and the potential of sport as a teaching methodology

Abstract: The idea that the mere transmission of theoretical knowledge is enough to reach the proenvironmental behavior is now refuted. Other factors such as situated and experiential learning are fundamental to the attainment of these objectives. In this field, nature-based sport could constitute one of the education methodologies. This article presents a theoretical and critical review of the current paradigms for teaching environmental education and the potential of sport as a teaching methodology. The findings reveal that the benefits of nature-based sport intersect with the objectives of environmental education particularly at a stage of environmental awareness acquisition.

Keywords: Nature. Environmental education. Sports.

La educación ambiental y el deporte en la naturaleza: Una reflexión crítica sobre los nuevos paradigmas de la educación ambiental y el potencial del deporte como una metodologia de la enseñanza

Resumen: La idea de que la mera transmisión de conocimientos teóricos y habilidades son suficientes para alcanzar el comportamiento pro-ambiental está refutada. Otros factores, como el aprendizaje experiencial y vivencial son fundamentales para el logro de estos objetivos. En este campo, el deporte en la naturaleza puede ser una de las metodologías para su formación. Este artículo presenta una parte teórica y crítica de los paradigmas actuales para la enseñanza de la educación ambiental y el potencial del deporte como una metodología de enseñanza. Los resultados revelan que los beneficios del deporte en la naturaleza se entrecruzan con los objetivos de la educación ambiental, especialmente en una etapa de adquisición de la conciencia ambiental.

Palavras clave: Naturaleza. Educación ambiental. Deportes. 


\section{REFERÊNCIAS}

BETRÁN, A.; BETRÁN, J. Las actividades físicas de aventura en la naturaleza. Estudio de la oferta y la demanda en el sector empresaria. Apunts, Barcelona, v. 57, p. 86-94, 1999.

BRASIL, F.; CARVALHO, Y. Pescadores Artesanais, Surfistas e a Natureza: Reflexões a partir de um Olhar da Educação Física. Movimento, Porto Alegre, v. 15, n. 1, p. 217-239, 2009.

BRYMER, E.; GRAY, T. Developing an intimate "relationship" with nature through extreme sports participation. Leisure/Loisir, Waterloo,v. 34, n. 4, p. 361-374, 2010.

CARVALHINHO, L. Os Técnicos e as Actividades de Desporto de Natureza - Análise da formação, funções, e competências profissionais. 2006. 339 f. Tese (Doutorado). Vila Real: Universidade de Trás-os-Montes e Alto Douro, 2006.

CARVALHINHO, L. et al. A emergência do sector de desporto de natureza e a importância da formação. Efdeportes, Buenos Aires, v. 14, n. 140, 2010. http:// www.efdeportes.com/efd140/desporto-de-natureza-e-formacao.htm. Acesso em: 30 nov. 2011.

COLE, D. Wilderness Recreation in the United States: Trends in Use, Users, and Impacts. International Journal of Wilderness, Idaho,v. 2, n. 3, p. 14-18, 1996.

DEARDEN, P.; ROLLINS, R. Parks and Protected Areas in Canada: Planning and Management. 3rd. Canada: Oxford University Press, 2009.

EAGLES, P. Trends in Park Tourism: Economics, Finance and Management1. Journal of Sustainable Tourism, London, v. 10, n. 2, p. 132-153, 2002. Disponível em: < http://www.tandfonline.com/doi/abs/10.1080/09669580208667158 >. Acesso em: 10 jul. 2010

FERREIRA, G. Environmental Education through Hiking: a qualitative investigation. Environmental Education Research, London, v. 4, n. 2, p. 177-185, 1998.

HAIDER, W.; PAYNE, R. Visitor planning and management. In: P.DEARDEN, R. R. (Ed.). Parks and Protected Areas In Canada - Planning and Management. 3rd. Canada: Oxford University Press, 2009. p.169-201.

INSTITUTO PORTUGUÊS DE QUALIDADE. Sistemas de gestão ambiental: Requisitos e linhas de orientação para a sua utilização: ISO 14001 de 2004. Almada, 2005. 
JENSEN, B.-.; SCHNACK, K. The Action Competence Approach in Environmental Education. Environmental Education Research, London, v. 3, n. 2, p. 163-178, 1997. Disponível em: < http://www.tandfonline.com/doi/abs/10.1080/ 1350462970030205 >. Acesso em: 15 set. 2011.

KOLLMUSS, A.; AGYEMAN, J. Mind the Gap: Why do people act environmentally and what are the barriers to pro-environmental behavior? Environmental Education Research, London,v. 8, n. 3, p. 239-260, 2002.

KYLE, G. et al. Effects of place attachment on users' perceptions of social and environmental conditions in a natural setting. Journal of Environmental Psychology, Amsterdam, v. 24, p. 213-225, 2004.

LAVE, J.; WENGER, E. Situated learning: legitimate peripheral participation. Cambridge: Cambridge University Press, 1991.

LEE, J.; WILLIAMS, M. International Research in Geographical and Environmental Education. International Research in Geographical and Environmental Education Research, London, v. 10, n. 3, p. 218-244, 2001. Disponível em: < http://www.tandfonline.com/doi/abs/10.1080/10382040108667443 >. Acesso em: 15 set. 2011.

LEE, T. How recreation involvement, place attachment and conservation commitment affect environmentally responsible behavior. Journal of Sustainable Tourism, London, v. 19, n. 7, p. 895-915, 2011. Disponível em: < http://www.tandfonline.com/ doi/abs/10.1080/09669582.2011.570345 >. Acesso em: 10 out. 2011.

LEUNG, Y.; MARION, J. Recreation Impacts and Management in Wilderness: A Stateof-Knowledge Review. In: WILDERNESS SCIENCE IN A TIME OF CHANGE CONFERENCE, 2000. Missoula, MT. U.S. Department of Agriculture, Forest Service, Rocky Mountain Research Station. p.23-48.

LIGHT, R. Situated learning in an Australian surf club. Sport, Education and Society, Leicestershire, v. 11, n. 2, p. 155-172, 2006.

MANNING, R. Parks and Carrying Capacity: Commons Without Tragedy. Washington: Island Press, 2007.

MARINHO, A. Lazer, Aventura e Risco: reflexões sobre atividades realizadas na natureza. Movimento, Porto Alegre, v. 14, n. 2, p. 181-206, 2008.

MATHEWS, F. Beyond modernity and tradition: A third way for development? Ethics and the Environment, Indiana,v. 11, n. 2, p. 85-113, 2006.

PRÖBSTL, U. et al. Introduction. In: PRÖBSTL, U.;WIRTH, V., et al (Ed.). Management of Recreation and Nature Based Tourism in European Forests. Berlim: Springer, 2010. cap. 1, p.1-9. 
RODRIGUES, C.; JUNIOR, L. Ecomotricidade: sinergia entre educação ambiental, motricidade humana e pedagogia dialógica. Motriz, Rio Claro, v. 15, n. 4, p. 987995, 2009. Disponível em: < http://www.periodicos.rc.biblioteca.unesp.br/index.php/ motriz/article/viewArticle/3252 >. Acesso em: 10 ago. 2010

RODRIGUES, L.; DARIDO, S. Educação Física escolar e meio ambiente: reflexões e aplicações pedagógicas. Efdeportes, Bueno Aires. n.100, 2006. Disponivel em: http://www.efdeportes.com/efd100/ma.htm. .Acesso em: 12 mar,2010.

ROSA, P.; ALMEIDA, M.; CARVALHINHO, L. Desporto de Natureza em Espaços Naturais: Contributo para o Ordenamento em Áreas Protegidas. 2011. $221 \mathrm{f}$. Dissertação (Mestrado). Rio Maior: Instituto Politécnico de Santarém: Escola Superior de Desporto de Rio Maior, 2011.

SANDELL, K.; ÖÖHMAN, J. Educational potentials of encounters with nature: reflections from a Swedish outdoor perspective. Environmental Education Research, London, v. 16, n. 1, p. 113-132, 2010. Disponível em: < http:// www.tandfonline.com/doi/abs/10.1080/13504620903504065 >. Acesso em: 20 jan. 2011.

SOARES, C.; PAIXÃO, J. Atividades de aventura e educação ambiental: possibilidades nas aulas de Educação Física escolar. Efdeportes, Buenos Aires, v. 142, 2010. Disponivel em: http://www.efdeportes.com/efd142/atividades-deaventura-e-educacao-ambiental.htm. Acesso em: 13 jan. 2011.

STEWART, A. M.; CRAIG, J. L. Predicting pro-environmental attitudes and behaviors: A model and a test. Journal of Environmental Systems, New York, v. 28, n. 4, p. 293-317, 2000.

TAHARA, A.; FILHO, S. Atividades físicas de aventura na natureza (AFAN) e academias de ginástica: motivos de aderência e benefícios advindos da prática. Movimento, Porto Alegre, v. 15, n. 3, p. 187-208, 2009.

Endereço para correspondência:

Paulo Filipe Rosa

Rua poeta Ruy Belo, número 23, 3ํㅡsquerdo

Cidade de Rio Maior, Portugal

Código Postal: 2040-323, Rio Maior

Recebido em: 22.04. 2012

Aprovado em: 14.06.2012

ovimento, Porto Alegre, v. 18, n. 03, p. 259-280, jul/set de 2012. 
